\section{'Congenital' Copper Deposit in the Rat}

THE striking increase in the copper concentration of the human liver, which begins during foetal life and reaches its maximum at birth, has not yet been satisfactorily explained. Since the importance of copper as a catalyst for hæmoglobin formation is now conclusively proved for many higher animals, most authors consider the 'congenital copper deposit', too, to be connected with this function. Two hypotheses have been suggested in this respect : $(a)$ copper is accumulated in the fœtal liver, because this is the chief site of blood formation during embryonic life ; (b) copper is stored in the foetal liver to compensate for the low copper content of milk during lactation, just as in the case of iron.

We have recently ${ }^{1}$ raised some criticism against both views, which we see now supported by our new findings in the rat species.

Figures for liver copper in young animals are somewhat meagre. Cunningham ${ }^{2}$ finds in seven species (bovine, sheep, pig, dog, guinea pig, rabbit and rat) similar conditions as in man, that is, highest values at birth and a rapid drop during the lactation period towards the low final level. Ramage ${ }^{3}$, Wilkerson ${ }^{4}$ and McFarlane and Milne ${ }^{5}$, on the other hand, working with goat, pig and chick embryos respectively, observe the peak already during fotal life and more or less low figures at birth.

During a study of iron, copper and hæmoglobin in white rats of various ages we were much surprised to find a marked increase of liver copper still after birth, the maximum not being reached before the 10-15th day of life (see accompanying table). Copper was determined by the dithiocarbamate method, non-hæmin iron by our hot pyrophosphate method ${ }^{8}$, hæmoglobin spectro-colorimetrically.

The phenomenon occurred with great regularity in each of seven litters which had been followed from birth on during the first weeks of life ; it contradicts the findings of Cunningham ${ }^{2}$ who, however, has only examined one litter. The peak was always reached between the 10th and 15th day, nearly coinciding with the opening of the rat's eyes. It may be recalled here that the rat is born in a rather embryonic state of development, a fact which is also reflected in its red blood picture?

In contrast to the liver, the percentage of copper in the whole body was found to drop gradually from birth on, as already shown by Lindow et al. ${ }^{8}$

Histological examination, kindly carried out by Dr. H. Karplus, of some of the livers revealed no correlation between copper content and hæmopoietic activity of the liver; that was to be expected since this activity is highest during the early foetal lifein birds and mammals - and has nearly disappeared at birth.

Our findings make hypothesis $(a)$ untenable, and

\begin{tabular}{|c|c|c|c|c|c|c|c|}
\hline \multirow{2}{*}{ Age (days) } & \multicolumn{2}{|c|}{ Liver-Copper } & \multicolumn{3}{|c|}{ Liver-Iron } & \multicolumn{2}{|c|}{ Hæmoglobin } \\
\hline & Average & Range & Avera & age & Range & Average & Range \\
\hline $0-1$ & 97 (13) & $62-133$ & 1790 & (16) & $1180-2650$ & $12 \cdot 1(60)$ & $7 \cdot 3-15 \cdot 3$ \\
\hline $5-7$ & $134 \quad(6)$ & $82-174$ & 1245 & $(5)$ & $650-2000$ & $8 \cdot 8 \quad(6)$ & $7 \cdot 8-9 \cdot 4$ \\
\hline $10-14$ & $206 \quad(7)$ & $133-270$ & 670 & (6) & $330-1130$ & $10 \cdot 9 \quad(7)$ & $9 \cdot 5-11 \cdot 8$ \\
\hline $15-17$ & $124(10)$ & $54-204$ & 340 & (4) & $137-500$ & - & \\
\hline $20-22$ & 10) & $5+204$ & 315 & $(9)$ & $82-1240$ & $10 \cdot 4 \quad(9)$ & $8 \cdot 0-13 \cdot 4$ \\
\hline $32-44$ & $33 \quad(8)$ & $21-50$ & 620 & (8) & $450-895$ & ${ }^{*} 12 \cdot 3 \quad(5)$ & $11 \cdot 6-13 \cdot 5$ \\
\hline
\end{tabular}

*30-34 days.

Copper, non-hæmin iron (mgm. per kgm. dry weight) and hæmoglobin (gm. \%) in yonng rats. (Figures in brackets indicate number of animals.) the same is true for the 'deposit' hypothesis $(b)$, since the increase occurs just during lactation, and in spite of a general decrease in the body copper concentration.

It appears to us that the rather dramatic accumula. tion of copper, occurring in different species at different times and paralleled by a similar increas in the copper content of young rapid-growing plant tissues, is not associated with the process of hæmoglobin formation but with growth and development, a view already suggested previously ${ }^{8,10,11}$. We are not yet prepared to say what particular process may be connected with the increase of liver copper ; but the recent identification of several oxidases as copper proteins and the isolation of similar compounds from blood and liver ${ }^{12}$ open many possibilities in this respect.

A detailed report of our experiments will be pub. lished elsewhere.

G. BRÜCKMANN.

Chemical Laboratory, S. G. ZONDEK.

Department of Internal Medicine,

Hadassah Municipal Hospital, Tel-Aviv.

May 7 .

${ }^{1}$ Brückmann, G., and Zondek, S. G., Biochem. J., 33, 1845 (1939). ${ }^{2}$ Cunningham, J. J., Biochem J., 25, 1267 (1931).

${ }^{3}$ Ramage, H., Biochem. J., 28, 1500 (1934).

4 Wilkerson, V. A., J. Biol. Chem., 104, 541 (1934).

${ }^{5}$ McFarlane, W. D., and Milne, H. I., J. Biol. Chem., 107, 309 (1934). - Brückmann, G., and Zondek, S. G., J. Biol. Chem. (in the press). "Wintrobe, M. M., and Shumacker, H., Amer. J. Anat., 58, 313 (1936).

${ }^{8}$ Lindow, C. W., Peterson, W. H., and Steenbock, H., J. Biol. Chem., 84, $419(1929)$

' Herkel, W., Ziegler's Beitr. path. Anat., 85, 513 (1930).

${ }^{10}$ Sheldon, T. H., and Ramage, H., Biochem. J., 25, 1608 (1931).

${ }^{11}$ Zondek, S. G., and Bandmann, M., Dt. Med. Wochenschr., 91 (1933).

${ }^{12}$ Mann, T., and Keilin, D., Proc. Roy. Soc., B, 126, 303 (1938).

\section{Use of Desiccated Chick Embryo in Tissue Culture Technique}

ONE of the difficulties inherent in tissue culture technique is the necessity for a regular supply of chick embryo extract, without which serial subcultures cannot be maintained. When fresh 9-11 day embryos are used, it is almost impossible to avoid a waste of material as it is necessary to incubate more eggs than will probably be required in order to ensure a sufficient supply of embryos.

At the commencement of the War, we decided to try desiccated 9-11 day chick embryos as a source of active principle, and, since November 1939, have successfully maintained a variety of cultures of normal and malignant tissues on fowl plasma clot, to which this extract was added. By parallel experiments, in which fresh embryo was compared with desiccated embryo, it was found that extracts of the two were equally effective. The desiccate was reconstituted by adding sterile distilled water up to the original volume. Aqueous extract prepared from such reconstituted material has better keeping qualities than fresh extract and can be used for ten days without apparent loss of efficacy.

In the dry state, the desiccate keeps without apparent loss of active principle for at least seven months; our desiccate has been kept in a refrigerator at $4^{\circ} \mathrm{C}$, but this precaution may not be necessary. The desiccate can be prepared at short 